\title{
APLICAÇÃO DE SÍLICIO NO SOLO: EFEITO NA EXPRESSÃO ENZIMÁTICA DE SEMENTES ORIUNDAS DE PLANTAS DE ARROZ SOB ESTRESSE SALINO
}

Elisa Lemes, Andre Oliveira de Mendonça, Leticia Dias, Andre Brunes, Sandro de Oliveira, Lilian Tunes, Antonio Albuquerque

Universidade Federal de Pelotas - UFPel. E-mail: lemes.elisa@yahoo.com.br

\section{RESUMO}

A utilização de silício pode acarretar em aumento da capacidade biológica da planta em resistir às condições adversas do meio ambiente. Diante disso, o presente trabalho teve por objetivo avaliar a expressão isoenzimática de sementes oriundas de plantas cultivadas com aplicação de cinza da casca de arroz, via solo, sob estresse salino. $O$ delineamento utilizado foi em blocos casualizados, em esquema fatorial A x B (Fator A- Cinco doses de cinza da casca de arroz aplicada via solo: 0; 500; 1000; 1500 e $2000 \mathrm{~kg}$ ha $^{-1}$; Fator B- Três concentrações salinas: 0, 4 e $8 \mathrm{mM}$ ), com quatro repetições. Foram realizados os testes de primeira contagem de germinação e germinação, e expressão dos sistemas isoenzimáticos glutamato oxaloacetato transaminase, álcool desidrogenase, glutamato desidrogenase e sorbitol. Variações nos quatro sistemas eletroforéticos analisados podem estar associados ao estresse salino causado durante o crescimento e desenvolvimento de plantas de arroz. O sistema isoenzimático glutamato oxaloacetato transaminase é uma ferramenta complementar à avaliação do potencial fisiológico de sementes de arroz.

Palavras-chave: isoenzimas; Oryza sativa L.; salinidade; sílica.

\section{APPLICATION OF SILICON TO THE SOIL: EFFECT ON ENZYMATIC EXPRESSION IN RICE SEED PRODUCED UNDER SALT STRESS}

\begin{abstract}
The silicon utilization may result in the increased biological ability of the plants to withstand the harsh conditions of the environment. In this sense, the study aimed to evaluate the effect of the application of rice husk ash to the soil in rice plants under salt stress on isoenzymes expression. The experimental design was a randomized block in factorial A $\times$ B (Factor A- Five doses of rice husk ash applied to soil: 0.0, 500, 1000, 1500, and $2000 \mathrm{~kg} \mathrm{ha}^{-1}$, Factor B- Three salt concentrations: 0, 4, and $8 \mathrm{mM}$ ), with four replications. Tests were the first count of germination and germination, and expression of isozyme systems glutamate oxaloacetate transaminase, alcohol dehydrogenase, glutamate dehydrogenase, and sorbitol. Variations in the all analyzed electrophoretic systems may be associated with salt stress caused during the growth and development of rice plants. The isoenzyme system glutamate oxaloacetate transaminase is a complementary tool to assess the physiological rice seed quality.
\end{abstract}

KeyWords: isoenzymes; Oryza sativa L.; salinity; silica.

\section{INTRODUÇÃO}

A salinidade é um dos mais importantes fatores de estresse abiótico, afetando diversos aspectos fisiológicos e bioquímicos das plantas, o que pode reduzir, significativamente, seus rendimentos. No Rio Grande do Sul, o principal sistema de irrigação da cultura do arroz é por inundação, podendo conduzir à salinização dos solos, especialmente em lavouras que utilizam a água proveniente de rios litorâneos, os quais estão sujeitos à salinização pela entrada de água do mar quando baixa o nível destes mananciais.

Neste sentido, a utilização de silício (Si) pode acarretar em aumento da capacidade biológica da planta em resistir às condições adversas do meio ambiente, pois mesmo não sendo essencial, o silício traz inúmeros benefícios para o desenvolvimento e crescimento das plantas, principalmente para as poáceas. A ação benéfica do $\mathrm{Si}$ tem sido associada a diversos 
efeitos indiretos, como aumento da eficiência da capacidade fotossintética, redução da transpiração, aumento da resistência mecânica das células (CAMARGO et al., 2007) e na adaptação das plantas a condições de estresses abióticos e bióticos.

Apesar de serem encontradas poucas informações na literatura sobre a aplicação de silício via solo em plantas cultivadas sob estresse salino, o uso de marcadores moleculares pode fornecer dados úteis sobre a estrutura $e$ diversidade genética das populações de plantas e possibilitar a visualização da expressão das enzimas nos diferentes estádios da planta (MCDONALD JR., 1999). As plantas sofrem alterações no seu metabolismo quando mantidas sob condições ambientais adversas. As isoenzimas são produtos da expressão gênica e consequentemente, altamente influenciadas pelo ambiente e pelo manejo, pois os genes que controlam a sua expressão manifestam-se em determinados estádios do desenvolvimento e em órgãos e tecidos específicos, ou ainda sob um determinado estímulo (RAMÍREZ et al., 1991).

Padrões enzimáticos de diversas enzimas importantes podem variar em resposta a fatores estressantes como seca, salinidade e alta intensidade luminosa (DUBEY; SHARMA, 1990). Dentre as enzimas relacionadas à qualidade fisiológica das sementes mais pesquisadas estão aquelas envolvidas no metabolismo de ligação nitrogênio-carbono, como a glutamato desidrogenase (GTDH) (CARVALHO et al., 2000) e as responsáveis pela oxidação de aminoácidos, fornecendo energia para o Ciclo de Krebs ou redução do $\alpha$-cetoglutarato para a síntese de novos aminoácidos, como por exemplo, a glutamato oxaloacetato transaminase (VIEIRA et al., 2009). Além dessas, pode-se citar a álcool desidrogenase $(A D H)$ que está relacionada à respiração anaeróbica, promovendo redução do acetaldeido a etanol (BUCHANAN et al., 2005) e a sorbitol desidrogenase (SBTDH) que catalisa a reação de remoção de hidrogênio do monossacarídeo sorbitol, possibilitando a degradação deste com posterior obtenção de energia para célula.

Diante do exposto, o objetivo do presente trabalho foi avaliar a expressão isoenzimática de sementes oriundas de plantas cultivadas com aplicação de cinza da casca de arroz, via solo, sob estresse salino.

\section{MATERIAL E MÉTODOS}

$O$ experimento foi desenvolvido em casa de vegetação e no Laboratório Didático de Análise de Sementes (LDAS) Flávio Farias Rocha, ambos pertencentes ao Programa de PósGraduação Ciência e Tecnologia de Sementes, do Departamento de Fitotecnia da Faculdade de Agronomia Eliseu Maciel (FAEM) da Universidade Federal de Pelotas (UFPel).

$O$ delineamento experimental foi em blocos casualizados, em esquema fatorial $A \times B$ (Fator A- Cinco doses da cinza da casca de arroz aplicada via solo: 0; 500; 1000; 1500; e $2000 \mathrm{~kg}$ ha $^{-1}$ e Fator B- Três concentrações salinas: 0, 4 e 8 $\mathrm{mM})$, com quatro repetições. Foram utilizadas sementes de arroz da cultivar IRGA 424 e, como fonte de silício foi utilizado cinza da casca de arroz carbonizada, a qual foi previamente moída para uniformizar a granulometria. Previamente à semeadura, as sementes foram tratadas com fungicida MAXIM XL ${ }^{\circ}$, inseticida CRUISER $350 \mathrm{FS}^{\circ}$ e polímero Color Seed ${ }^{\circ}$, utilizando-se 150, 150 e $300 \mathrm{~mL} 100 \mathrm{~kg}$ de sementes ${ }^{-1}$, respectivamente, com um volume de calda de $1200 \mathrm{~mL} 100 \mathrm{~kg}$ de sementes $^{-1}$, o qual foi completado com água. 0 recobrimento foi realizado conforme metodologia descrita por Nunes (2005), que consiste num método manual em sacos plásticos (3 L).

A semeadura foi realizada em vasos, preenchidos com 7 litros de solo peneirado, coletado do horizonte A1 de um PLANOSSOLO HÁPLICO Eutrófico solódico (STRECK et al., 2008), pertencente à unidade de mapeamento Pelotas. A adubação foi realizada de acordo com os resultados da análise de solo e recomendações da Comissão de Química e Fertilidade do Solo $\mathrm{RS} / \mathrm{SC}$ (2004). A calagem foi realizada trinta dias antes da semeadura. A aplicação das doses de silício foi realizada no momento da semeadura, a qual foi incorporada ao solo até uma profundidade de 0,1 metro. Foi utilizado como tratamento o equivalente a 0,$0 ; 500 ; 1000 ; 1500$ e $2000 \mathrm{~kg}$ de silício ha ${ }^{-1}$. Para tanto, considerouse o volume da camada arável do solo em um hectare em torno de 2 milhões de litros, estas quantidades foram transformadas para o volume dos vasos. Considerando que a cinza de casca de arroz carbonizada tem aproximadamente $92 \%$ de silíca foi utilizado o equivalente a 0,$0 ; 1,90 ; 3,80$; 5,$71 ; 7,61$ g de cinza de casca de arroz carbonizada, respectivamente, para cada dose, em cada unidade experimental. Após a semeadura a irrigação foi realizada diariamente 
no período da manhã com as concentrações de cloreto de sódio $(\mathrm{NaCl})$, mantendo-se o solo próximo à capacidade de campo até o estabelecimento definitivo da lâmina de água, realizado aos 30 dias após a emergência, conduzindo desta forma o experimento até a fase de maturação de campo.

Foram realizadas avaliações da qualidade fisiológica das sementes produzidas, através dos testes de: Germinação (G)- realizado segundo as Regras para Análise de Sementes - RAS (BRASIL, 2009). Primeira contagem da germinação (PCG)realizado conjuntamente ao teste de germinação. Além destes, avaliou-se a expressão isoenzimática, através de eletroforese, nas sementes produzidas, sendoanalisadas as isoenzimas GOT (Glutamato oxaloacetato transaminase), ADH (Álcool desidrogenase), GTDH (Glutamato desidrogenase) e SBTDH (Sorbitol desidrogenase). Foram utilizadas dez sementes produzidas em função da aplicação de doses de silício via solo e diferentes concentrações salinas, maceradas em gral de porcelana, para cada unidade experimental. A avaliação consiste na utilização de $200 \mathrm{mg}$ do extrato vegetal colocados em tubos eppendorf, acrescidos de solução extratora (tampão do gel + 0,15 \% de 2-mercaptoetanol), na proporção 1:2 $(p / v)$. A eletroforese foi realizada em géis de poliacrilamida $7 \%$, colocando-se $20 \mu \mathrm{L}$ de cada amostra, em orifícios feitos com o auxílio de um pente de acrílico. Três aplicações (repetições) para cada uma das amostras foram realizadas. Os padrões enzimáticos foram analisados pelo sistema de tampões, descrito por Scandalios (1969). Os géis foram colocados em cubas eletroforéticas verticais, mantidas em câmara fria, com temperatura entre 4 e $6{ }^{\circ} \mathrm{C}$. As migrações eletroforéticas foram realizadas com uma diferença de potencial de $10 \mathrm{~V} \mathrm{~cm}^{-1}$, até que a linha frontal, formada pelo azul de bromofenol, atingisse $9 \mathrm{~cm}$ do ponto de aplicação. Os géis de eletroforese foram fixados em solução 5-5-1, de água destilada: metanol: ácido acético, sendo revelados conforme Scandalios (1969) e Alfenas (1998).

Os dados do experimento foram submetidos à análise de variância e havendo significância, realizou-se comparação de médias através do teste de Tukey para o fator concentração salina e regressão polinomial para - fator dose de silício, todos a 5\% de probabilidade. Para a análise da expressão de isoenzimas, a interpretação dos resultados foi baseada na análise visual dos géis de eletroforese, levando em consideração a presença/ausência, bem como a intensidade de cada uma das bandas eletroforéticas.

\section{RESULTADOS E DISCUSSÃO}

Em relação ao teste de primeira contagem de germinação foi constatado interação entre $\mathrm{o}$ fator dose de silício e concentração salina (Tabela 1). Observou-se que, em geral, a concentração $0 \mathrm{mM}$ de sal foi superior as demais concentrações, não diferindo na dose de $500 \mathrm{~kg}$ de silício ha ${ }^{-1}$ da concentração salina de $4 \mathrm{mM}$ e na dose de $2000 \mathrm{~kg}$ de silício ha 1 nas concentrações 4 e $8 \mathrm{mM}$ de sal. A germinação não apresentou interação entre os fatores, no entanto, a média obtida na concentração de $0 \mathrm{mM}$ foi superior às demais concentrações salinas, o que demonstra o efeito negativo da salinidade sobre a porcentagem de plântulas normais (Tabela 1). Deuner et al. (2011) trabalhando com sementes de genótipos de feijão-miúdo, também constataram que o aumento da concentração de sal causou efeito negativo à primeira contagem de germinação $\mathrm{e}$ germinação. Em contrapartida, Castellanos et al. (2016) verificaram que a irrigação com água salina favoreceu a porcentagem de plântulas normais obtidas pelo teste de germinação e primeira contagem da germinação. 
Tabela 1. Porcentagem de plântulas normais obtidas no teste de primeira contagem de germinação (PCG) e germinação (G) de sementes de arroz da cultivar IRGA 424, produzidas em função da aplicação de doses de silício via solo e diferentes concentrações salinas.

\begin{tabular}{|c|c|c|c|c|c|c|}
\hline \multirow{2}{*}{$\begin{array}{c}\text { Dose Silício } \\
\left(\mathrm{kg} \mathrm{ha}^{-1}\right)\end{array}$} & \multicolumn{3}{|c|}{ PCG } & \multicolumn{3}{|c|}{ G } \\
\hline & $0 \mathrm{mM}$ & $4 \mathrm{mM}$ & $8 \mathrm{mM}$ & $0 \mathrm{mM}$ & $4 \mathrm{mM}$ & $8 \mathrm{mM}$ \\
\hline 0 & $93 a$ & $88 \mathrm{~b}$ & $86 \mathrm{~b}$ & 97 & 96 & 95 \\
\hline 500 & $94 \mathrm{a}$ & 93 a & $88 \mathrm{~b}$ & 97 & 96 & 95 \\
\hline 1000 & 95 a & $92 \mathrm{~b}$ & $90 \mathrm{c}$ & 98 & 96 & 96 \\
\hline 1500 & $95 \mathrm{a}$ & $91 \mathrm{~b}$ & $89 \mathrm{~b}$ & 97 & 96 & 95 \\
\hline 2000 & $91 \mathrm{a}$ & $89 a$ & $89 a$ & 97 & 95 & 95 \\
\hline Média & 94 & 90 & 88 & $97 a$ & $96 \mathrm{~b}$ & $95 \mathrm{c}$ \\
\hline C.V (\%) & \multicolumn{3}{|c|}{1,6} & \multicolumn{3}{|c|}{1,2} \\
\hline
\end{tabular}

*Médias seguidas da mesma letra minúscula na linha, para cada variável, não diferem entre si pelo teste de Tukey a $5 \%$ de probabilidade.

Na Figura $1 \mathrm{~A}$, observa-se que para as concentrações salinas de 0 e $4 \mathrm{mM}$ houve um incremento na porcentagem de plântulas normais até a dose de silício de 950 e $900 \mathrm{~kg} \mathrm{ha}^{-1}$, respectivamente, com posterior decréscimo até a dose mais elevada. A concentração salina de 8 $\mathrm{mM}$ teve seu ponto de máxima germinação em $1150 \mathrm{~kg}$ de silício ha ${ }^{-1}$, sendo que em doses mais elevadas ocorreu redução no incremento nessa variável. Comparando as três concentrações salinas, verifica-se que na maior concentração salina são necessárias doses maiores de silício para se obter o ponto de máxima eficiência. Para a variável germinação não foi observado diferença significativa entre as doses de silício (Figura 1 B). Semelhantemente, Toledo et al. (2011) em sementes de aveia branca e Castellanos et al. (2016) com sementes de trigo não encontraram diferença significativa para a germinação das sementes com o aumento das doses de silício.

Figura 1. Porcentagem de plântulas normais obtidas no teste de primeira contagem de germinação (A) e germinação (B) de sementes de arroz da cultivar IRGA 424, produzidas em função da aplicação de doses de silício via solo e diferentes concentrações salinas.

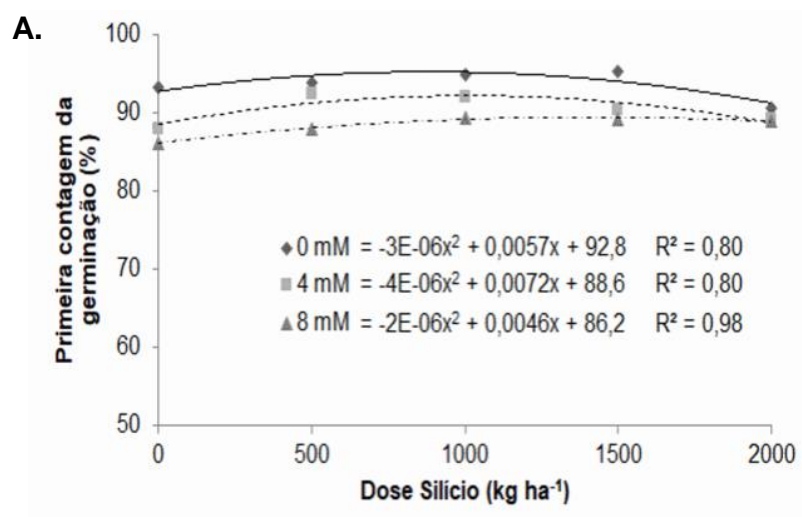

A partir da análise dos sistemas isoenzimáticos foi possível visualizar que houve variação na intensidade das bandas. No sistema eletroforético da GOT, constatou-se a expressão de 2 alelos (GOT 1 e GOT 2). Na dose zero de silício, observa-se que há um aumento na expressão da enzima com o aumento das concentrações salinas. $O$ aumento na expressão desta enzima é inversamente proporcional a

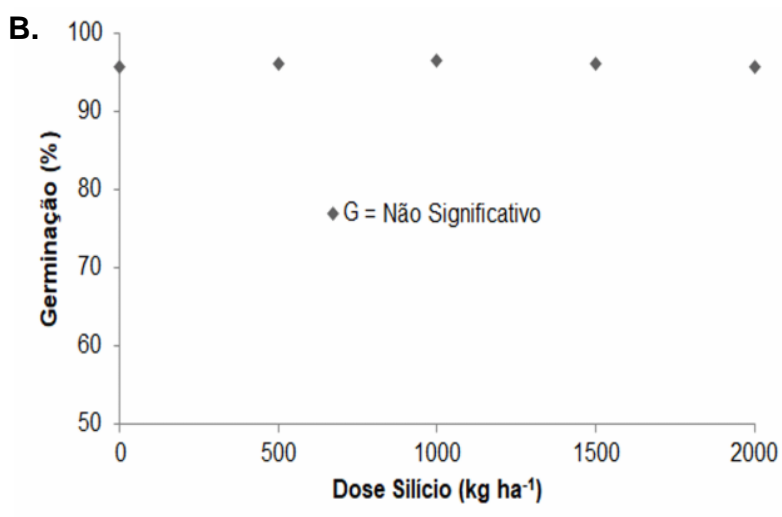

qualidade das sementes, sendo responsável pela oxidação de aminoácidos, fornecendo energia para o Ciclo de Krebs ou redução do $\alpha$ cetoglutarato para a síntese de novos aminoácidos, como fonte de energia ao embrião em desenvolvimento (VIEIRA et al., 2009). Assim, é possível que variações na concentração salina possam estar envolvidas na expressão da isoenzima GOT, conforme resultados obtidos nos 
testes de qualidade fisiológica das sementes produzidas sem aplicação do elemento químico.

Nas doses de 500 e 2000 kg de silício ha ${ }^{-1}$, foi possível observar similaridade na intensidade das bandas desta enzima (Figura $2 \mathrm{~A}$ ). 0 estresse salino tem sido um grande obstáculo para 0 sucesso do uso de solos afetados por sais para a produção agrícola de arroz irrigado. Segundo Zhu et al. (2004) o silício atua na diminuição desse tipo de estresse por reduzir a permeabilidade da membrana plasmática e lipídica e também por atuar na manutenção da integridade e funcionalidade das mesmas. Observa-se que, com a aplicação de silício nas doses de 1000 e 1500 kg $\mathrm{ha}^{-1}$, a expressão da enzima diminui nas concentrações de 8 e $4 \mathrm{mM}$, respectivamente, corroborando com os resultados obtidos nos testes de vigor, onde a aplicação de silício resultou em incrementos. Em trabalho realizado por Tunes (2009), foi observado incremento de bandas para a enzima GOT com a deterioração das sementes, o que pode ser atribuído ao aumento na atividade metabólica com o processo deteriorativo.

Figura 2. Padrões eletroforéticos obtidos com o sistema isoenzimático Glutamato Oxaloacetato Transaminase (A), Álcool Desidrogenase (B), Glutamato Desidrogenase (C) e Sorbitol Desidrogenase (D) de sementes de arroz da cultivar IRGA 424, produzidas em função da aplicação de doses de silício via solo e diferentes concentrações salinas

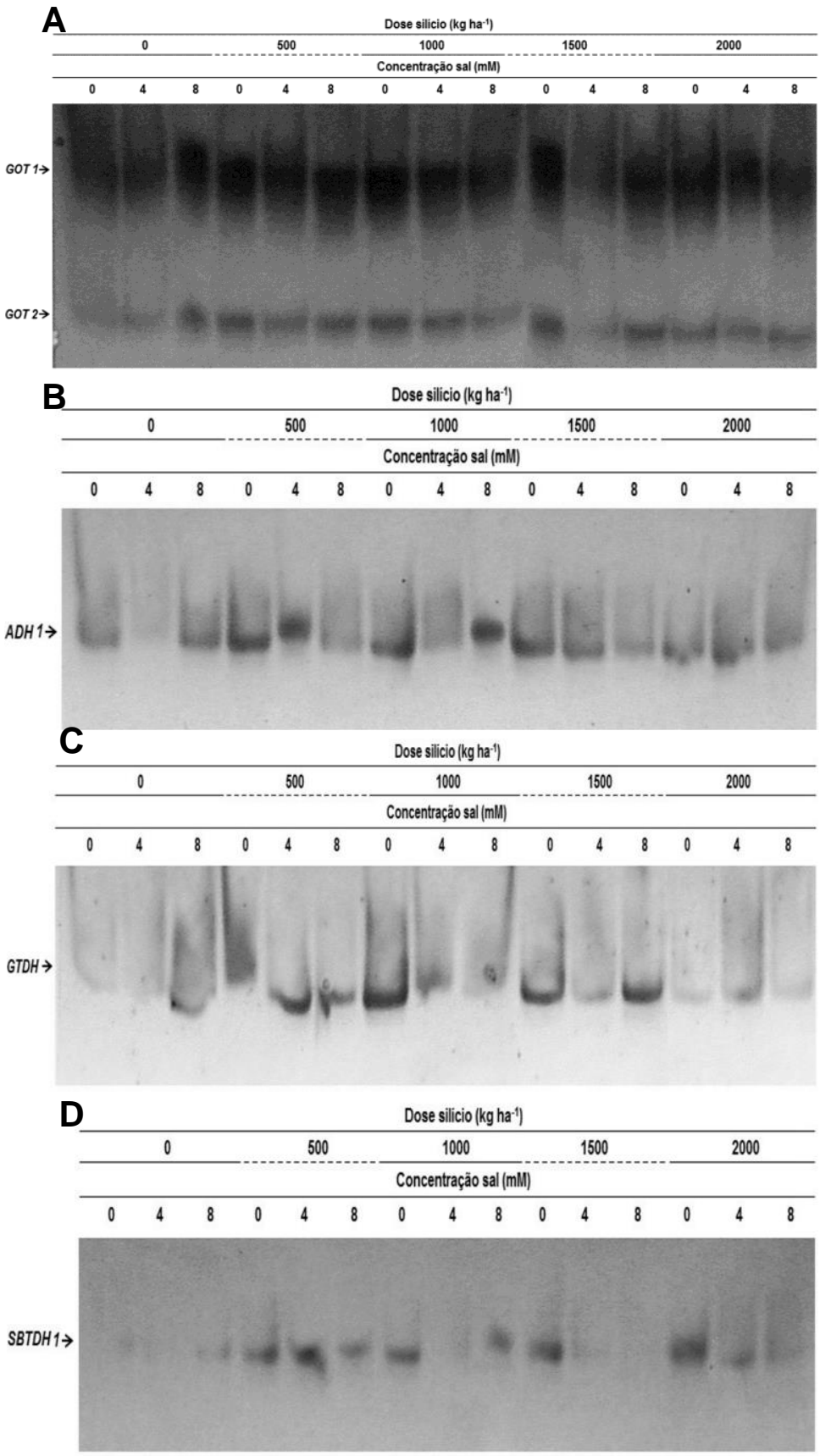


A ADH atua no processo respiratório, reduzindo substâncias tóxicas às sementes, como acetaldeído a etanol, que são produzidos, quando as células passam a respirar anaerobicamente (FARIA et al., 2003). O processo de acúmulo de etanol envolve a oxidação de NADH e resulta na produção de pequenas quantidades de ATP, fundamental para a sobrevivência de várias espécies sob condições de anoxia. Para a álcool desidrogenase foi constatado presença de um alelo (ADH 1), onde verificou-se que sem a aplicação de silício, a concentração salina de 8 $\mathrm{mM}$ apresentou aumento na expressão em relação as demais concentrações (Figura 2 B). Para as doses de 500 e $1500 \mathrm{~kg}$ de silício ha ${ }^{-1}$, a expressão da enzima foi maior nas concentrações de 0 e $4 \mathrm{mM}$ de $\mathrm{NaCl}$. Na dose de $1000 \mathrm{~kg}$ de silício ha ${ }^{-1}$, observou-se maior intensidade da banda nas concentrações salinas de 0 e $8 \mathrm{mM}$. No entanto, na aplicação de $2000 \mathrm{~kg}$ de silício ha ${ }^{-1}$, observou-se similaridade na expressão da referida enzima. $O$ acetaldeído acelera a deterioração das sementes, portanto, com o aumento da atividade da ADH, as sementes ficam mais protegidas contra a ação deletéria deste composto. De acordo com Tunes (2009), a expressão desta enzima é exclusiva nas sementes, diminuindo à medida que o processo de germinação avança e o processo aeróbico de geração de energia começa a ser predominante.

Para a expressão da enzima GTDH observou-se um alelo (GTDH 1) no sistema isoenzimático (Figura $2 \mathrm{C}$ ). Nas doses 0 e $500 \mathrm{~kg}$ de silício ha ${ }^{-1}$, observou-se maior expressão desta enzima com 0 aumento progressivo das concentrações de sal. Embora se tenha observado maior expressão da GTDH, pode-se inferir que a enzima apresentou pouca ou nenhuma atividade. A GTDH apresenta alta correlação entre redução da atividade e redução da qualidade fisiológica (BRANDÃO-JÚNIOR et al., 1999), fato que foi detectado pelos testes de viabilidade e vigor no presente trabalho. Concordando com o autor, na dose de $1000 \mathrm{~kg}$ de silício ha $^{-1}$, observou-se comportamento inverso, com decréscimo em sua expressão à medida que aumentaram as concentrações salinas. Para a dose de $1500 \mathrm{~kg}$ de silício ha ${ }^{-1}$, a concentração salina $4 \mathrm{mM}$ apresentou menor expressão. Já na dose $2000 \mathrm{~kg}$ de silício ha ${ }^{-1}$, as concentrações de 0 e $8 \mathrm{mM}$ de sal, apresentaram menor expressão (Figura 2 C).
A SBTDH apresenta-se como oxiredutora que catalisa a reação de remoção de hidrogênio do monossacarídeo sorbitol, possibilitando a degradação deste com posterior obtenção de energia para a célula (Figura 2 D). Sem aplicação de silício e com o aumento da concentração salina de 0 até $8 \mathrm{mM}$, observou-se incremento na expressão da enzima. Na dose de $500 \mathrm{~kg}$ de silício $\mathrm{ha}^{-1}$, não observou-se disparidade na expressão entre as concentrações de $\mathrm{NaCl}$. Na dose de 1000 $\mathrm{kg}$ de silício $\mathrm{ha}^{-1}$, as concentrações salinas de 0 e $8 \mathrm{mM}$ apresentaram incremento na expressão. Já nas doses de 1500 e $2000 \mathrm{~kg}$ de silício ha ${ }^{-1}$, a ausência de sal, resultou em maior expressão da banda. Basavarajappa et al. (1991) afirmam que a perda de atividade de desidrogenase em sementes submetidas a um estresse, pode estar associada a baixos níveis de produção da ATP e reduzidas taxas de ATP e GTP dependente da síntese de proteína. No entanto, Tunes et al. (2010) não verificaram decréscimo na expressão da mesma enzima, conforme aumento da concentração salina em sementes de cevada.

De acordo com Tunes et al. (2009), o uso de marcadores para verificação de alterações em enzimas é uma ferramenta de grande valor para o controle de qualidade de sementes, permitindo diagnosticar o estado fisiológico das mesmas e, em determinados casos, inferir sobre causas da perda de viabilidade e vigor. A partir dos quatro sistemas eletroforéticos analisados, pode-se inferir que ocorreram variações no padrão de expressão das isoenzimas nas sementes produzidas, em função do cultivo das plantas sob aplicação de doses de silício via solo e estresse salino.

\section{CONCLUSÕES}

Variações nos quatro sistemas eletroforéticos analisados (GOT, ADH, GTDH e SBTDH) pode estar associado ao estresse salino causado durante o crescimento e desenvolvimento de plantas de arroz. O sistema isoenzimático glutamato oxaloacetato transaminase é uma ferramenta complementar à avaliação do potencial fisiológico de sementes de arroz.

\section{REFERÊNCIAS}

ALFENAS, A.C. Eletroforese de isoenzimas e proteínas afins. Viçosa: UFV, 1998. 574p. 
BASAVARAJAPPA, B.S.; SHETTY, H.S.; PRAKASH, H.S. Membrane deterioration and other biochemical chances, associated with accelerated ageing of maize seeds. Seed Science and Technology, v.19, n.2, p. 279-286, 1991.

BRANDÃO-JUNIOR, D.S.; CARVALHO, M.L.M.; VIEIRA, M.G.G.C. Variações eletroforéticas de proteínas e isoenzimas relativas à deterioração de sementes de milho envelhecidas artificialmente. Revista Brasileira de Sementes, v.21, p. 114-121, 1999. https://doi.org/10.17801/01013122/rbs.v21n1p114-121

BRASIL. Ministério da Agricultura, Pecuária e Abastecimento. Regras para análise de sementes. Ministério da Agricultura, Pecuária e Abastecimento. Secretaria de Defesa Agropecuária. Brasília: Mapa/ACS, 2009. 395p.

BUCHANAN, B.B.; GRUISSEM, W.; JONES, R.L. Biochemistry \& Molecular Biology of plants. Rockville: American Society of Plant Physiologists, 2005. 1367p.

CAMARGO, M.S.; KORNDÖRFER G.H.; PEREIRA H.S. Solubilidade do silício em solos: influência do calcário e ácido salicílico aplicados. Bragantia, v. 66, n.4, p.637-647, 2007. https://doi.org/10.1590/S000687052007000400014

CARVALHO, M.L.M.; VIEIRA, M.G.G.C.; PINHO, E.R.V. Técnicas moleculares em sementes. Biotecnologia, Ciência \& Desenvolvimento, v.3, n.17, p.44-47, 2000.

CASTELLANOS, C.I.S.; ROSA, M.P.; DEUNER, C.; BOHN, A.; BARROS, A.C.S.A; MENEGHELLO, G.E. Aplicação ao solo de cinza de casca de arroz como fonte de silício: efeito na qualidade de sementes de trigo produzidas sob stresse salino. Revista de Ciências Agrárias, v.39, n.1, p.95-104, 2016. https://doi.org/10.19084/RCA15011

\section{COMISSÃO DE QUÍMICA E FERTILIDADE DO SOLO}

RS/SC. Manual de adubação e de calagem para os Estados do Rio Grande do Sul e de Santa Catarina. 10. ed. Porto Alegre, Sociedade Brasileira de Ciência do Solo, 2004. 400p.

DEUNER, C.; MAIA, M.S.; DEUNER, S.; ALMEIDA, A.S.; MENEGHELLO, G.E. Viabilidade e atividade antioxidante de sementes de genótipos de feijãomiúdo submetidos ao estresse salino. Revista Brasileira de Sementes, v.33, n.4, p.711-720, $2011 . \quad$ https://doi.org/10.1590/S0101$\underline{31222011000400013}$

DUBEY, R.S.; SHARMA, K.N. Behavior of phosphatases en germinating rice in relation to salt tolerance. Plant. Physiology \& Biochemistry, v.28, p.17-26, 1990.

FARIA, L.C.; COSTA, J.G.C.; RAVA, C.A.; PELOSO, M.J.D.; MELO, L.C.; CARNEIRO, G. E.S.; SOARES, D.M.; DIAZ, J. L.C; ABREU, A.F.B.; FARIA, J.C.; SARTORATO, A.; SILVA, H.T.; BASSINELLO, P.Z.; ZIMMERMANN, F.J.P. BRS Requinte: nova cultivar de feijoeiro comum de tipo de grão carioca com retardamento do escurecimento do grão. Santo Antônio de Goiás, GO. Embrapa Arroz e Feijão, 2003. (Comunicado Técnico, 65).

MCDONALD JR., M.B. Seed deterioration: physiology, repair and assessment. Seed Science and Technology, v. 27, n. 1, p. 177-237, 1999.

NUNES, J.C. Tratamento de semente - qualidade e fatores que podem afetar a sua performance em laboratório. Syngenta Proteção de Cultivos, 2005. $16 p$.

RAMIREZ, H.; CALDERON, A.; ROCCA, W. Técnicas moleculares para evaluar y mejorar el germoplasma vegetal. In: Rocca, W.; Mroginski, L. (Ed). Cultivo de Tejidos en la Agricultura: Fundamentos y aplicaciones. Cali: CIAT, 1991. p. 825-856

SCANDALIOS, J.G. Genetic control of multiple molecular forms of enzymes in plants: a review. Biochemical Genetics, v.3, p. 37-39, 1969. https://doi.org/10.1007/BF00485973

STRECK, E.V.; KÄMPF, N.; DALMOLIN, R.S.D.; KLAMT, E., NASCIMENTO, P.C.; SCHNEIDER, P.; GIASSON, E.; PINTO, L.F.S. Solos do Rio Grande do Sul. 2. ed. Porto Alegre: EMATER/RSASCAR, 2008. p. 222.

TOLEDO, M. Z.; GARCIA, R. A.; MERLINA, A; FERNANDES, D. $M$. Seed germination and seedling development of white oat affected by silicon and phosphorus fertilization. Scientia Agricola, v. 68, n. 1, p. 18-23, 2011. 
https://doi.org/10.1590/S0103-

$\underline{90162011000100003}$

TUNES, L.M. Atributos fisiológicos de qualidade de sementes de cevada sobre diferentes épocas de colheita e durante o armazenamento. 2009. 102p. Dissertação (Mestrado) - Faculdade de Agronomia Eliseu Maciel, Pelotas-RS, 2009.

TUNES, L.M.; BADINELLI, P.G.; BARROS, A.C.S.A.; CASTRO, M.A.S. Alterações fisiológicas e enzimáticas em sementes de cevada sob diferentes condições de armazenamento. Magistra, v. 21, n. 3, p. 154-164, 2009.

TUNES, L.M; PEDROSO, D.C.; MENEGHELLO, G.E.; CASTRO, M.A.S.; BARROS, A.C. S.A.; BADINELLI, P.G.; MUNIZ, M.F.B. Perfil enzimático em sementes de cevada em resposta a diferentes concentrações salinas. Interciência, v.35, n.5, p.369-373, 2010.

VIEIRA, E.S.N.; VON PINHO, E.V.R.; CARVALHO, M.G.G.; SILVA, P.A. Caracterização de cultivares de soja por descritores morfológicos e marcadores bioquímicos de proteínas e isoenzimas. Revista Brasileira de Sementes, v.31, p. 86-94, 2009. https://doi.org/10.1590/S0101$\underline{31222009000100010}$

ZHU, Z.J.; WEI, G.Q.; LI, J.; QIAN, Q.Q.; YU, J.Q. Silicon alleviates salt stress and increases antioxidant enzymes activity in leaves of saltstressed cucumber (Cucumis sativus L.). Plant Science, v.167, p.527-533, 2004. https://doi.org/10.1016/j.plantsci.2004.04.020

Recebido para publicação em 13/12/2017

Revisado em 27/03/2018

Aceito em 31/03/2018 